Chapter 13

\title{
Biosynthesis of Lipids and Hydrocarbons in Algae
}

\author{
Masato Baba and Yoshihiro Shiraiwa \\ Additional information is available at the end of the chapter \\ http://dx.doi.org/10.5772/56413
}

\section{Introduction}

Lipids function as important storage compounds to maintain cellular activities. Lipids store high reducing power and energy since those biosynthetic processes require high amount of reducing cofactors and ATP. Storage lipids do not cause any chemical effect on cellular activity such as osmolarity, $\mathrm{pH}$ and ion strength because of its hydrophobicity. Membrane lipids such as phospholipids, carotenoids, and cholesterols play a housekeeping role. In addition, some of lipids function as protein modifiers or signaling molecules.

Recently, plant oils are gathering keen interest as a source of renewable energy according to rapid increase in social demands for establishing a low-carbon-society. However, oil production for biofuels and biorefinery using higher plants and crops is strongly worried for competing with food production and to increase those market prices. Therein, algae came into play a new oil-producing organism since algae do not compete with food production. According to their high productivity per unit area, prokaryotic photoautotrophs such as cyanobacteria and eukaryotic algae such as protists are expected to become a promising feedstock in future (Gong \& Jiang, 2011).

Although numerous kinds of lipids exist in nature, main carbon chain of the molecules is almost derived from limited numbers of precursor molecules such as fatty acids and isoprenoids. Interestingly, some parts of the synthetic pathways of lipids are quite different among animals, higher plants, cyanobacteria and some eukaryotic microalgae. Although there is quite few information on lipid biosynthesis and metabolism in algae, it is noteworthy that most of biosynthetic pathways of hydrocarbons such as fatty acid- and isoprene-derived hydrocarbon have been well characterized in microalgae.

In this chapter, we will introduce recent progresses on lipid and hydrocarbon biosynthetic pathways in microalgae: First, unique features of algal lipid synthetic pathways mostly hypothesized by advanced DNA sequencing technique although those are not well proved 
experimentally yet. Second, two factors for hydrocarbon biosynthesis in microalgae characterized recently by a combination of expressed sequence tags (EST) analysis and novel enzyme characterization. Those are: (1) decarbonylase to produce fatty acid-derived hydrocarbons in cyanobacteria and (2) isoprene-derived hydrocarbon biosynthetic pathway in a representative oil-producing colonial microalga, Botryococcus braunii. Third, the mechanism for carbon flow and energy balance in lipid and hydrocarbon biosynthetic pathways. Finally, we will describe a future perspective of algal lipid biosynthetic pathways and its application to biofuel production.

\section{Unique features of algal lipid biosynthetic pathways}

Although there is no agreed definition and classification of "lipids" (The AOCS Lipid Library, http://lipidlibrary.aocs.org/), here we define a term "lipid" as follows: 1) it is biological component of and derived from organisms; 2 ) it is basically very soluble in organic solvents but not in water; 3) it contains hydrocarbon group in its structure. We adopt biosynthetic classification to categorize lipids such as fatty acid, isoprene or others of unique lipids as shown in Table 1, instead of a conventional lipid classification such as simple lipid, derived lipid, complex lipid, and so on. Here we used the term "lipids" for compounds composed of only carbon, hydrogen, and oxygen.

Table 1 indicates the list of various lipids and their functions. Although numberless lipids exist in nature, main carbon chain of the molecules is mostly derived from fatty acids, isoprenes and their homologous compounds via some synthetic pathways. Recent progress in genome/ transcriptome sequencing technology and its computational analysis on similarity of those base sequences among organisms, namely in silico analysis, enable us rapid prediction of metabolic pathway even in uncharacterized organism. Owing to the modern in silico analyses, some unique features of algal lipid biosynthesis are starting to be enlightened. Interestingly, some parts of the synthetic pathways are quite different among animals, higher plants, cyanobacteria and eukaryotic algae.

\begin{tabular}{lll}
\hline Name & Structure & Function \\
\hline Fatty acid & $\mathrm{C}_{2 n}$-/straight-carbon chainwith carboxyl group & Membrane component;Bioactivity \\
\hline Polyketide & Various carbon chain with polyketone group & Antibiotic; Bioactivity \\
\hline Glyceride & Ester of fatty acid \& glycerol & Common storage lipid \\
\hline Terpenoid & $\mathrm{C}_{5 n-} /$ branched-carbon chain;isoprene derivate & Bioactivity \\
\hline Steroid & Tri-terpenoid derivate & Common hormone \\
\hline Carotenoid & Tetra-terpenoid derivate;conjugated double bond; & Pigment \\
& absorbent & \\
\hline
\end{tabular}

Table 1. Various lipids and their functions 


\subsection{Fatty acid biosynthesis}

Acetyl-coenzyme A ( $\mathrm{CoA})$ is a universal carbon donor for fatty acid biosynthesis. Acetyl-CoA is supplied via multiple paths from various origins and then subsequently metabolized into malonyl-acyl carrier protein (ACP) by sequential reactions. One molecule of ATP (1ATP) is used for the carboxylation of acetyl unit to produce one malonyl unit. In general, fatty acid biosynthesis utilizes acetyl-CoA and malonyl-ACP as starting substrates and acetyl unit donors. Primarily, butyryl $\left(C_{4}\right)$-ACP is synthesized from acetyl $\left(C_{2}\right)-C o A$ and malonyl $\left(C_{3}\right)-A C P$ via sequential reactions of condensation, decarboxylation, and reduction of non-malonyl-ACP derived keto unit. Two molecules of NADPH (2NADPH) is used for the reduction of keto group. Accordingly, 1ATP and 2NADPH are consumed to elongate chain of fatty acid molecule by adding $\mathrm{C}_{2}$-saturated carbon unit in fatty acid biosynthesis. Acyl-ACP is elongated up to $\operatorname{acyl}\left(\mathrm{C}_{16 \text { or } 18}\right)$-ACP. Molecules with $\mathrm{C}_{2 \mathrm{n}}$-carbon chain are widely distributed among various organisms and those of $\mathrm{C}_{2 \mathrm{n}-1}$-carbon chain are synthesized from $\mathrm{C}_{2 \mathrm{n}}$-compounds by carbon-loss

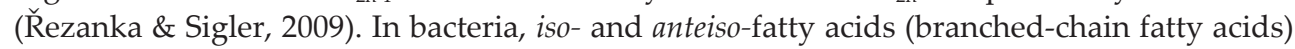
are synthesized from amino-acid-derived precursors with branch (Kaneda, 1991). ACP is subsequently removed from acyl $\left(\mathrm{C}_{16}\right.$ or $\left.{ }_{18}\right)$ - ACP to form fatty acid $\left(\mathrm{C}_{16 \text { or } 18}\right)$. The fatty acids synthesized on the plastid envelopes are excreted into cytosol by accompanying probably with the process of binding of CoA (Joyard et al., 2010). Oppositely, fatty acid is necessary to be activated by the binding of ACP for passing through the cell membrane in the cyanobacteria Synechocystis species.

In any step, a synthesized carbon chain can be metabolized into various products including glycerolipids, triacylglycerides (TG), phospholipids and glycolipids (Joyard et al., 2010). Fatty acids synthesized excessively are stored as TG in most eukaryotes. Usually prokaryotes do not accumulate TG although Actinomycetes and a few other bacteria exceptionally synthesize TG (Alvarez \& Steinbüchel, 2002).

Same fatty acids as metabolites are widely observed in various organisms but their biosynthetic pathways are different depending on classification. There are four known groups of enzyme(s) for fatty acid biosynthesis; type-I fatty acid synthase (FAS), type-II FAS, particular elongases, and enzymes for catalyzing the reversal of $\beta$-oxidation. Typically, animals and fungi possess type-I FAS which is a large multi-functional enzyme with multiple functional domains (Chan \& Vogel, 2010; Joyard et al., 2010). Bacteria, plastids and mitochondria have type-II FAS which is composed of four subunit proteins such as ß-ketoacyl-ACP synthase (KAS), B-ketoacyl-ACP reductase, B-hydroxyacyl-ACP dehydratase and enoyl-ACP reductase (Chan \& Vogel, 2010; Joyard et al., 2010; Hiltunen et al., 2010). A trypanosomatid Leismania major possesses three elongases instead of above mentioned FASs for fatty acid biosynthesis (Lee et al., 2006). In a microalga Euglena gracilis fatty acids are synthesized de novo via the reversal pathway of $\beta$ oxidation under anaerobic conditions (Hoffmeister et al., 2005; Inui et al., 1984). As such, wide variation seems to exist among organisms but detailed information on fatty acid biosynthesis is not well understood in algae.

One of model organism Chalmydomonas reinhardtii (Chlorophyta) possesses type-II FAS gene which is homologous to that of land plants (Riekhof et al., 2005). Land plants have both plastidal- and mitochondrial-FASs which exhibit different substrate specificity (Yasuno et al., 
2004). Mitochondrial ACP-type enzymes are well characterized especially in the yeast Saccharomyces cerevisiae (Hiltunen et al., 2010). In the green alga C. reinhardtii, FAS is thought to be localized both in the plastid and the mitochondrion individually since respective FAS gene is represented as single gene in each organelle (Riekhof et al., 2005). Expressed sequence tags (ESTs) of Chlorophyta Botryococcus braunii Bot-88-2 (race A) contained a partial sequence of type-I FAS (accession number: FX056119) which is partially similar to animal FAS (Baba et al., 2012a). However, further information of complete genome sequence is necessary to confirm it. In E. gracilis which has triple-layer envelope, there are five fatty acid synthetic pathways located in four subcellular compartments; the type-I FAS system in the cytosol, two type-II FAS systems in the plastid, fatty acid synthesis associated partly with wax ester fermentation in the microsomes (see 3.1.4. Wax ester) and a malonyl-ACP independent process located in the mitochondria. E. gracilis synthesizes wax esters when cells were grown under either heterotrophic or anaerobic conditions (Hoffmeister et al., 2005). Wax ester fermentation under anaerobic conditions produces ATP in net profit while general malonyl-ACP-dependent fatty acid synthesis consumes ATP (Inui et al., 1982). Fatty acids supplied for wax ester production are de novo synthesized by acetyl-CoA condensing reaction which is similar to the reversal pathway of $\beta$-oxidation, where trans-2-enoyl-CoA reductase contributes instead of acyl-CoA dehydrogenase (mitochondrial $ß$-oxidation enzyme) or acyl-CoA oxidase (peroxisomal $\beta$ oxidation enzyme) (Hoffmeister et al., 2005; Inui et al., 1984). The trans-2-enoyl-CoA reductase reaction is a key step in the reversal pathway of $B$-oxidation. The direction of the pathway is $\mathrm{O}_{2}$-dependently determined to proceed irreversibly under aerobic conditions since the key enzyme pyruvate:NADP ${ }^{+}$oxidoreductase is sensitive to $\mathrm{O}_{2}$ (Tucci et al., 2010). The reversal pathway may be essential to maintain the redox balance in the mitochondria under anaerobic conditions (Tucci et al., 2010). Such hypothesis is supported by another report which demonstrated that ß-oxidation can be reversed in genetically engineered Escherichia coli (Dellomonaco et al., 2011). In mammalian mitochondria, the reversal pathway functions for only elongation process due to substrate specificity of mammal enoyl-CoA reductase and therefore the pathway contributes to short-chain fatty acid elongation process (Inui et al., 1984).

\subsection{Fatty acid elongation}

$\mathrm{C}_{18}$-Fatty acid can be further elongated via the fatty acid elongation pathway. Fatty acid elongation process is very similar to that of the fatty acid synthesis although acyl-CoA and malonyl-CoA are used as a substrate. In the process, $1 \mathrm{ATP}$ and $2 \mathrm{NADPH}$ are required for $\mathrm{C}_{2}{ }^{-}$ unit elongation of saturated carbon chain since CoA-activation is not essential as suggested by another study (Hlousek-radojcic et al., 1998). Fatty acid elongation reaction site was shown to be located in the endoplasmic reticulum (Kunst \& Samuels, 2009). In contrast to FAS system, all known elongation systems are basically compatible and functions simultaneously. Fatty acid elongase constitutes an enzyme complex of four subunits which is similar to type-II FAS; namely, ß-ketoacyl-CoA synthase (KCS), ß-ketoacyl- CoA reductase, ß-hydroxyacyl-CoA dehydratase and enoyl-CoA reductase. There are two different KCSs; namely "elongation of very long-chain fatty acid" (ELOVL or merely ELO)-type elongase which contributes to sphingolipid biosynthesis and "fatty acid elongation" (FAE)-type elongase which contributes to plant seed TG or wax biosynthesis (Venegas-Calerón et al., 2010). Typically, animals and 
fungi possess ELO-type while land plants possess FAE-type. In some cases, ELO and FAE subunits are inaccurately referred as mere "elongase" since heterologous expression of single gene for KCS often results in successful elongation of acyl-CoA by the help of the other subunit of the host (typically, yeast and land plant Arabidopsis thaliana).

Poly unsaturated very long-chain fatty acid (PUVLCFA, PULCA, VLC-PUFA, etc.) is one of elongated fatty acids (e.g. Arachidonic acid, Eicosapentaenoic acid, and Docosahexaenoic acid). PUVLCFA is commonly observed in algae such as Euglenophytes, diatoms (Phaeodactylum tricornutum, Thalassiosira pseudonana) and haptophytes (Emiliania huxleyi, Isochrysis galbana, Pavlova salina) which possess desaturase/elongases to produce EPA and DHA from $C_{18}$ fatty acid and derivatives (Venegas-Calerón et al., 2010). This elongation is shown to be catalyzed by ELO-type fatty acid elongase. On the other hand, contribution and physiological function of FAE-type elongase has not been proved in microalgae yet. Macroalgae produce short and long-chain aldehydes (Moore, 2006). These metabolites are suggested to be produced from PUVLCFA although the detailed synthetic pathway is almost unknown. Long-chain aldehyde producing reaction was reported to be catalyzed by lipooxygenase which functions to oxygenize and cleave PUVLCFA at a specific position to form short-chain metabolites (Moore, 2006).

\subsection{Polyketide biosynthesis}

Polyketide includes various complex compounds such as antibiotics (e.g. erythromycin, tetracycline, lovastatin) (Staunton \& Weissman, 2001). Polyketide biosynthesis is similar to $\mathrm{C}_{4}$ and longer fatty acid synthesis except successive reduction of keto-group and utilizes various $\mathrm{ACP} / \mathrm{CoA}$ compounds as its substrate. Mycolic acids, extremely large fatty acids (ca. $\mathrm{C}_{90}$ ) in the cell envelope of mycobacteria (Verschoor et al., 2012), are synthesized by condensation of two VLCFA acyl-CoA molecules via polyketide biosynthesis (Portevin et al., 2004).

There are three types of polyketide syntheses (PKSs): type-I PKS which is a large multifunctional enzyme in the consequence of multiple functional domains, type-II PKS which is composed of monofunctional proteins to form complex and type-III PKS which resembles chalcone synthase catalyzing the committed step in flavonoid biosynthesis in higher plants and some bryophytes (Shen, 2003). Type-I PKSs are further classified into two, namely iterative and non-iterative (modular) types. Bacteria possess type-I to III of PKSs. Fungi and animal typically possess type-I iterative PKS which is closely related each other (Jenke-Kodama \& Dittmann, 2009). Interestingly, there is evolutional connection between PKSs and FASs (JenkeKodama \& Dittmann, 2009; John et al., 2008; Sasso et al., 2011).

In the genomes of chlorophyta (C. reinhardtii, Chlorella variabilis, two Ostreococcus species, etc.), heterokontophyta (Aureococcus anophagefferens), and haptophyceae (Emiliania huxleyi and Chrysochromulina polylepis), "non-iterative" type-I PKS is coded but not in land plant, rhodophyta (Cyanidioschyzon merolae and Galdieria sulphuraria), Stramenopiles (Thalassiosira pseudonana, Phaeodactylum tricornutum, two Phytophthora species), and Euglenozoa (Trypanosoma brucei, Trypanosoma cruzi and Leishmania major) (Sasso et al., 2011). Polyketide synthesis plays a role in biosynthesis of cyanobacterial toxin, microcystin (Jenke-Kodama \& Dittmann, 2009). Dinoflagellate toxins are also polyketides although its synthetic pathway remains unknown 
because of technical restrictions (Sasso et al., 2011). In addition, biosynthetic processes of polyketides in macroalgae are one of important targets to be urgently elucidated.

\subsection{Terpenoid biosynthesis}

Terpenoid which is composed of branched $\mathrm{C}_{5 n}$ carbon unit are synthesized by condensation of $\mathrm{C}_{5}$ isoprene units (as isopentenyl diphosphate (IPP) and its isomer dimethylallyl diphosphate (DMAPP) in vivo) (Bouvier et al., 2005). In general, isoprene unit is supplied via either or both mevalonic acid (MVA) pathway or/and methylerythritol phosphate (MEP) pathway (or non-mevalonic acid pathway). MVA pathway is located in the cytosol of Archaea and eukaryotes or in the peroxisome (Lohr et al., 2012). In MVA pathway, three molecules of acetylCoA are condensed into DMAPP through MVA and then IPP by sequential reactions, using $3 \mathrm{ATP}$ and 2NADPH. The MEP pathway is known to be located in the cytosol of bacteria including cyanobacteria and in the stroma of plastids in plants and eukaryotic algae (Joyard et al., 2009). In MEP pathway, pyruvate and glyceraldehyde-3-phosphate (GAP) react to form IPP or DMAPP via MEP using energy of three high-energy phosphate bonds on either ATP or CTP and reducing power from at least 1NADPH and four reducing coenzymes (not completely identified yet) (Hunter, 2007). One molecule of $\mathrm{CO}_{2}$ is released in MVA and MEP pathway respectively. In land plants, isoprene units can be exchanged through chloroplast envelope by that MVA and MEP pathways complement each other. However, any protein for isoprene unit exchange has not been isolated so far (Bouvier et al., 2005; Joyard et al., 2009; Lohr et al., 2012).

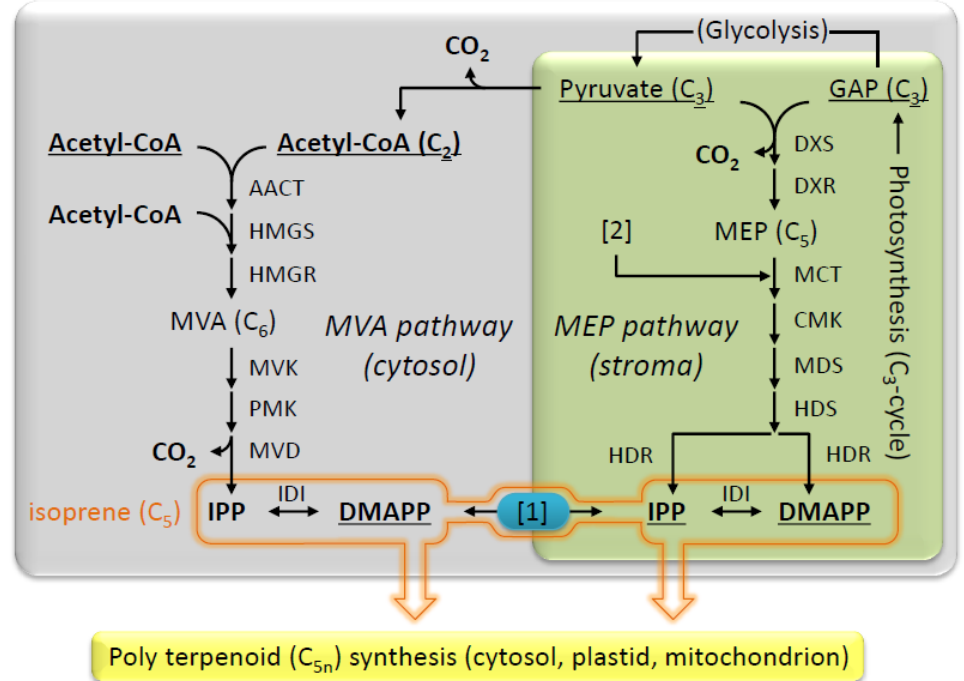

Figure 1. Pathway for terpenoid biosynthesis 
Primary and terminal molecules are underlined respectively. Substrates multiply used are shown in bold. [1]: putative Isoprene transporter. [2]: a predicted junction from the pentose phosphate pathway to the MEP pathway in cyanobacteria. AACT, acetoacetyl-CoA thiolase; CMK, 4-(cytidine 5'-diphospho)-2-C- methylerythritol kinase; DXR, 1-deoxy-D-xylulose 5phosphate reductoisomerase; DXS, 1-deoxy-D-xylulose 5-phosphate synthase; HDR, 4hydroxy-3-methylbut-2-en-1-yl diphosphate reductase; HDS, 4-hydroxy-3-methylbut-2-en-1yl diphosphate synthase; HMGS, 3-hydroxy-3-methylglutaryl-CoA synthase; HMGR, 3hydroxy-3-methylglutaryl-CoA reductase; IDI, isopentenyl diphosphate:dimethylallyl diphosphate isomerase; MCT, 2-C-methyl-D-erythritol 4-phosphate cytidylyltransferase; MDS, 2-C-methyl-D-erythritol 2,4-cyclodiphosphate synthase; MVD, mevalonate-5-diphosphate decarboxylase; MVK, mevalonate kinase; PMK, 5-phosphomevalonate kinase.

In silico analysis suggested that algae have enzymes for terpenoid biosynthesis which resembles with those in land plants (Lohr et al., 2012; Sasso et al., 2011). On the other hand, MVA pathway genes are often lost in some algae although such algal unique system remains to be understood in future work (Lohr et al., 2012; Sasso et al., 2011). EST analysis on race A and B of $B$. braunii revealed that MEP pathway genes are actively expressed but not MVA pathway genes. Some secondary symbiotic algae possess a mosaic MVA pathway which involves enzymes originated from both primary and secondary hosts (Lohr et al., 2012). MEP pathway connected with the pentose phosphate pathway was observed in a species of cyanobacteria although detailed mechanism is still not clear (Poliquin et al., 2004).

IPP and DMAPP are metabolically conjugated by condensation and dephosphorylation to produce polyterpenoid. No ATP or reducing power is required when isoprene units get into condensation reaction by head-to-tail conjunction (e.g. farnesyl pyrophosphate formation while $1 \mathrm{NADPH}$ is required in case of tail-to-tail condensation (e.g. squalene formation). Polyterpenoid is individually or cooperatively synthesized either in the cytosol, plastid or mitochondrion(Bouvier etal., 2005; Joyard etal., 2009; Lohretal., 2012). Each terpenoid condensation enzyme has particular specific to isoprene molecules such as mono-/sesqui-/di-/tri-/tetra-terpene, respectively. Unlikely land plant, the biosynthesis of isoprene in green macroalgae proceeds via MEP pathway in the plastid (Lohretal., 2012) and it functions to produce special natural products such as bioactive halogenated poly terpenoid (Moore, 2006). Vanadium bromoperoxidase is an abundant enzyme to produce brominated products in all classes of marine macroalgae and vanadium iodoperoxidase is also identified and characterized (Moore, 2006). However, vanadium chloroperoxidase is not yet identified despite the abundance of chlorinated compounds in algae. These haloperoxidases catalyze both halogenation and cyclization to produce various unique halogenated cyclic terpenoid in macrolagae, but such unique isoprene condensing enzyme is not yet identified in microalgae (Sasso et al., 2011).

\section{Hydrocarbon biosynthesis in algae}

Table 2 shows a list of lipids and hydrocarbons which can be candidates for renewable energy sources. These compounds are metabolites derived from the elemental lipids shown in Table 


\begin{tabular}{|c|c|c|}
\hline Name & Structure & Function \\
\hline Odd-chain fattyhydrocarbon & Hydrocarbonfrom fatty acid $\left(\mathrm{C}_{2 n-1}\right)$ & Unknown \\
\hline Wax ester & Ester of fatty acid \& fatty alcohol & Cuticle component \\
\hline Alkenones & $\begin{array}{l}\text { trans-unsaturated-/straight-carbon chainwith } \\
\text { ketone group }\end{array}$ & Storage lipid? \\
\hline Heterocyst glycolipid & Alcohol-/ketone-glycoside & Cell wall component \\
\hline $\begin{array}{l}\text { Even-chain fatty } \\
\text { hydrocarbon }\end{array}$ & $\begin{array}{l}\text { Hydrocarbon } \\
\text { from fatty acid (C2n) }\end{array}$ & Unknown \\
\hline Olefinichydrocarbon & $\begin{array}{l}\text { Hydrocarbon from fatty acidwith multiple } \\
\text { double bonds }\end{array}$ & Unknown \\
\hline Terpenoid hydrocarbon & Hydrocarbon from terpenoid & Unknown \\
\hline
\end{tabular}

Table 2. Lipids and hydrocarbons for renewable energy source

1. Their pool sizes of metabolites in cells and production capability largely varies among species and even strains of a certain species. The most extreme example can be seen in a colonial oil-producing green alga B. braunii: a certain strain dominantly produces odd-chain fatty hydrocarbons while another produces terpenoid derived hydrocarbons and those strains are classified as race $\mathrm{A}, \mathrm{B}$ and $\mathrm{L}$.

Microalgal species/strains nominated as oil-producer are simply classified into three groups by their main products: namely, hydrocarbons, TG/free fatty acids and the other lipids. For example, bacteria (Schirmer et al., 2010), a unicellular green alga Pseudochoricystis ellipsoidea (Satoh et al., 2010), a colonial green alga B. braunii race A (Yoshida et al., 2012) accumulate fatty hydrocarbons. According to a recent review (Yoshida et al., 2012), B. braunii race B and L and a heterotrophic Labyrinthulea Aurantiochytrium sp. produce terpenoid-derived hydrocarbons. Green algae C. reinhardtii, Chlorella vulgaris, Chlorella protothecoides, diatoms, Nannochloropsis spp. usually produce and accumulate TG and free fatty acids. E. gracilis Z produces wax ester and accumulate it in the cell (Inui et al., 1982). Haptophytes, but only five species, produce long-chain ketones, called as "alkenones" (Laws et al., 2001; Eltgroth et al., 2005; Toney et al., 2012). Red and green macroalgal species, Gracilaria salicornia and Ulva lactuca, respectively, contain only limited amounts of lipids including arachidonic acid and Docosapentaenoic acid 
ranging 1 2\% of dry weight (Tabarsa et al., 2012). Recent big news was that genetic transformation by the particle-gun bombardment method was successfully established in alliphatic hydrocarbon producing photosynthetic eukaryote Pseudochoricystis ellipsoidea (Trebouxiophyceae) (Imamura et al., 2012). This achievement may open a new trail toward the genetic manipulation of metabolism for algal biofuel production.

\subsection{Fatty hydrocarbons and the other fatty acid derivates}

Alliphatic carbon-chain is a ubiquitous structure which exists in the molecules produced via fatty acid biosynthesis in organisms. In this part we introduce some fatty acid derivatives and their molecular properties and biosynthetic pathways.

\subsubsection{Odd-chain fatty hydrocarbon}

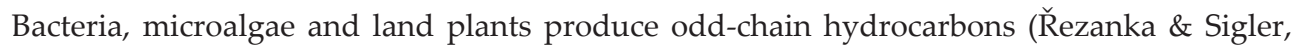
2009; Tornabene, 1981). Plant wax constitutes of odd-chain hydrocarbons without any branching, namely fatty hydrocarbons (Jetter \& Kunst, 2008). This type of hydrocarbons is suggested to be produced via the decarbonylation pathway (Jetter \& Kunst, 2008; Schirmer et al., 2010). First, acyl-CoA is reduced to form fatty aldehyde using $1 \mathrm{NADPH}$ as a reductant cofactor (Schirmer et al., 2010; Willis et al., 2011). In pea, the decarbonylation reaction is catalyzed by a membrane-bound enzyme, fatty acyl-CoA reductase (Cheesbrough \& kolattukudy, 1984; Vioque \& Kolattukudy, 1997) which is also present in the race A of B. braunii (Wang \& Kolattukudy, 1995).

A cyanobacterium Synechococcus elongatus PCC7942 has fatty acyl-ACP reductase which prefers acyl-ACP, not acyl-CoA, as substrate (Schirmer et al., 2010). Bacterial gene for the aldehyde-forming fatty acyl-CoA reductase was identified, but not eukaryotic gene yet. Fatty aldehyde is decarbonylated to form odd-chain fatty hydrocarbons with a release of carbon monoxide. Such aldehyde decarbonylase activity was successfully determined in land plants (Jetter \& Kunst, 2008), a colonial green alga B. braunii, and bacteria (Schirmer et al., 2010), but its gene was identified only in bacteria at present (Schirmer et al., 2010). Using microsomal preparations of B. braunii, alkane was proved to be synthesized from fatty acid and aldehyde only under anaerobic conditions (Dennis \& Kolattukudy, 1991). The aldehyde decarbonylase is a cobalt porphyrin enzyme which was suggested to locate in the microsomes (Dennis \& Kolattukudy, 1992). However, it is not known yet how intracellular hydrocarbons are transferred to extracellular space in race A of B. braunii (Casadevall et al., 1985; Largeau et al., 1980; Templier et al., 1992). In addition, an enzyme for the synthesis of odd-chain fatty hydrocarbons is unidentified yet since the product of the enzyme was different from native hydrocarbons of $B$. braunii by lacking terminal double bond seen in the natural product. Although decarbonylation reaction does not require any reductant, the reaction of in vitro decarbonylation from octadecanal to heptadecane was observed only in the presence of ferredoxin, ferredoxin reductase and NADPH. This result suggest essential requirement of reductant for aldehyde decarbonylase to exhibit activity in the cyanobacterium Nostoc punctiforme PCC73102 (Schirmer et al., 2010). 


\subsubsection{Wax ester}

Wax esters consist of fatty acids (acyl-CoAs in vivo) and fatty alcohols and are one of components of plant cuticles or seed oils (Jetter \& Kunst, 2008; Kunst \& Samuels, 2009). E. gracilis produces wax esters under either heterotrophic or anaerobic conditions (Inui et al., 1982). Wax esters are produced by condensation of fatty acids and primary alcohols which are synthesized from acyl-CoAs (see also 3.1.5. Even-chain fatty hydrocarbon). Wax ester synthase/acyl-CoA:diacylglycerol acyltransferase (WSD1) is a condensation enzyme identified in A. thaliana (Li et al., 2008). In E. gracilis, both NADH-requiring alcohol-forming fatty acyl-CoA reductase (EgFAR) and wax synthase (EgWS) are already identified and the sequences of those genes showed similarity with those of jojoba (land plant) (Teerawanichpan \& Qiu, 2010). EgWS utilizes a broad range of fatty acyl-CoAs and fatty alcohols as substrates with the preference towards myristic acid and palmitoleyl alcohol (Teerawanichpan \& Qiu, 2010). Those substrates are suggested to be produced via various fatty acid synthetic pathways in this alga (see 2.1. Fatty acid biosynthesis).

\subsubsection{Alkenones}

At least five species of haptophyceae (Chrysotile lamellose, Emiliania. huxleyi, Gephyrocapsa oceanica, Isochrysis galbana, Pseudoisochrysis sp.) were reported to accumulate highly alkenes, alkenoates (PUVLCFA-methyl/ethyl esters) and alkenones (PUVLC ketones) (Eltgroth et al., 2005; Laws et al., 2001; Toney et al., 2012). In this section, we call those compounds "alkenones" for our convenience. "Alkenones" are discriminated from the other lipids by 2 to 4 trans-carbon double bonds stocked under low temperature conditions, and by its remarkable length (about $\mathrm{C}_{38}$ ). "Alkenones" are suggested to be synthesized near the chloroplast, and then stored in the intracellular lipid body (Eltgroth et al., 2005). Mechanisms for alkenone biosynthesis and its desaturation are not known yet. Alkenones may act as a storage lipid since behavior of alkenones was shown to be similar to TG in the other algae functioning storage lipids (Eltgroth et al., 2005).

\subsubsection{Heterocyst glycolipid}

The heterocyst of cyanobacterium Anabaena sp. PCC 7120 is surrounded by cell wall involving unique glycolipids as a component (heterocyst glycolipid: HGL) (Bauersachs et al., 2009; Awai \& Wolk, 2007). HGL may be a good source of biofuel since such sugar-conjugated molecule (aglycon) is changed to $\mathrm{C}_{26-28}$ fatty polyhydric alcohol or ketone by removing sugar residues. HGL is known to be biosynthesized from fatty polyhydric alcohol via an unknown pathway which may be composed of fatty acid and/or polyketide synthetic enzymes (Awai \& Wolk, 2007; Bauersachs et al., 2009) as its mechanisms including transportation of HGL during heterocyst development has been well studied (Bauersachs et al., 2009; Nicolaisen et al., 2009). Fatty polyhydric alcohol is metabolized to glycoside by the catalysis of glycosyltransferase (HGL formation protein: HglT) (Awai \& Wolk, 2007). 


\subsubsection{Even-chain fatty hydrocarbon}

The bacterium Vibrio furnissi M1 was suggested to synthesize even-chain fatty hydrocarbons by the reduction of fatty acids through primary fatty alcohols (Park, 2005). Primary fatty alcohols are commonly synthesized from acyl-CoA by either one-step or two-step reductions. The one-step reduction is catalyzed by "alcohol-forming" fatty acyl-CoA reductase of which gene was already identified in bacteria (Willis et al., 2011) and various eukaryotes such as land plants and Euglena (Teerawanichpan \& Qiu, 2010; Vioque \& Kolattukudy, 1997). The two-step reduction reactions are catalyzed by two enzymes: namely, "aldehyde-forming" fatty acylCoA reductase and then fatty aldehyde reductase of which gene is identified only in bacteria (Wahlen et al., 2009). In the two-step reductive reactions, 2NADPH are necessary to reduce acyl-CoA to primary fatty alcohol. However, mechanism for consequential reactions to form even-chain fatty hydrocarbon by reducing fatty alcohol has not been identified yet (Park, 2005) but elucidation of the mechanism and knowledge on its distribution among species are very important for the progress of biofuel production.

\subsubsection{Olefinic hydrocarbon}

Olefinic hydrocarbons contain many unsaturated bonds in the molecule. Ole (olefin) $A B C D$ is a gene set harbored in bacteria and catalyzes the production of an olefinic hydrocarbon molecule by head-to-head condensation reaction (Beller et al., 2010; Sukovich et al., 2010a; Sukovich et al., 2010b). The head-to-head condensation reaction is summarized as follows: 1) a carboxyl group $\left(\mathrm{R}_{1}-\mathrm{COOH}\right)$ of fatty acid $\mathrm{X}$ is reduced to a carbonyl group $\left.\left(\mathrm{R}_{1}-\mathrm{CHO}\right) ; 2\right)$ the carbonyl (or thioester $\left(\mathrm{R}_{1}\right.$-CO-S-CoA with carbon number $\mathrm{x}$ )) group of $\mathrm{X}$ reacts with an alphacarbon of another fatty acid $\mathrm{Y}\left(\mathrm{R}_{2}-\mathrm{H}_{2}-\mathrm{COOH}\right.$ with carbon number $\left.\mathrm{y}\right)$ to combine by forming a hydroxyl group (-OH) and releasing one carbon molecule; 3 ) the hydroxyl group changes into a carbon double bond $\left.\left(\mathrm{R}_{1}-\mathrm{C}=-\mathrm{R}_{2}\right) ; 4\right)$ the reduction of the carbon double bond results to produce hydrocarbon molecule with carbon number of $[x+y-1]$ (Albro \& Dittmer, 1969). So, acyl-CoA can react with an alpha-carbon of fatty acid instead of carbonyl unit of the aldehyde (Sukovich et al., 2010a). As the gene set oleABCD was recently identified, further kinetic and phylogenic studies can be performed.

\subsection{Hydrocarbon biosynthesis from isoprene: A novel terpenoid hydrocarbon biosynthetic pathway in a colonial green alga Botryococcus braunii (race B)}

A colonial green alga B. braunii produces hydrocarbon up to $75 \%$ of its dry weight (Yoshida et al., 2012). B. braunii is generally classified into three races by its products: race A produces oddchain fatty hydrocarbons (alkadiene, alkatriene); race B (triterpene) and L (tetraterpene) produces hydrocarbons from isoprene, namely terpenoid hydrocarbons (Yoshida et al., 2012). B. braunii cells are botryoidally-aggregated by a network of covalently and/or non-covalently conjugated hydrocarbon molecules to build colony structure: namely, as structural hydrocarbons (Metzger et al., 1993; Metzger et al., 2007; Metzger et al., 2008). Extracellular space is filled with liquid hydrocarbons being discriminated from the structural hydrocarbons (Weiss et al., 2012). Hydrocarbon biosynthesis in the race A is partially understood but no recent progress 
was reported (see 3.1.1. Odd-chain fatty hydrocarbon). Properties of the race B hydrocarbons are mostly well-known although the race $\mathrm{L}$ is still enigmatic.

The race $B$ hydrocarbons are methylsqualene and botryococcene which are specifically produced by B. braunii. The amount of the race B hydrocarbons accumulated in the colony did not decrease in the dark, suggesting that extracellular hydrocarbons are a physiologically inactive storage compounds (Sakamoto et al., 2012). $\mathrm{C}_{5}$-isoprene unit for synthesizing hydrocarbon molecules is supplied via MEP pathway in B. braunii (Sato et al., 2003) (see 2.4. Terpenoid biosynthesis). The enzyme 1-deoxy-D-xylulose-5-phosphate synthase catalyzes the first step of the MEP pathway and its three distinct isoforms are well-characterized (Matsushima et al., 2012). ESTs of most genes in the MEP pathway, but never the MVA pathway, are already obtained by transcriptome analysis although those are not completely cloned and characterized yet (Ioki et al., 2012a; Ioki et al., 2012b). Botryococcene is known to be synthesized via a similar pathway to squalene biosynthesis besides of cleavage manner of cyclopropane base in a precursor, presqualene pyrophosphate (PSPP) (Metzger \& Largeau, 2005; Banerjee et al., 2002). Squalene synthase, which is widely observed in eukaryotes, catalyzes two step reactions: namely, (1) condensation of two farnesyldiphosphates (FPP, triterpene) to form PSPP and (2) dephospholylation, cyclopropane cleavage, carbon bond reformation and NADPH-dependent reduction of PSPP to produce squalene (Okada, 2012; Jennings et al., 1991). These two reactions are catalyzed at the domain 3 and 4 for $1^{\text {st }}$ reaction and the domain 5 for $2^{\text {nd }}$ reaction of six domains sequentially (Gu et al., 1998). Botoryococcus squalene synthase (BSS) was isolated by methods of homology screening of cDNA library based on its putative homologous sequence obtained by the degenerate PCR method to already known squalene synthase (Okada et al., 2000). BSS expressed in E. coli produced only squalene but not botryococcene (Okada et al., 2000). Squalene synthase like-1 (SSL-1) is a protein which is homologous to BSS possessing quite different amino acid sequence at the domain 5 (Niehaus et al., 2011). The purified SSL-1 did not function to produce neither botryococcene nor squalene in vitro. Instead, SSL-1 stimulates botryococcene production when it was added to B. braunii cell extracts. Furthermore, over expression of SSL-1 in FPP accumulating yeast resulted in the accumulation of presqualene alcohol (dephospholylated PSPP) in the cells. These results suggested that SSL-1 functions as PSPP synthase but subsequent reactions for squalene synthesis are catalyzed by other enzymes (Niehaus et al., 2011). SSL-2 and SSL-3 are proteins which are also homologous to BSS (Niehaus et al., 2011). SSL-2 catalyzes two NADPH-dependent reactions for the production of squalene from PSPP and bisfarnesyl ether with a little squalene from FPP. SSL-3 catalyzes a NADPH-dependent reaction to form botryococcene from PSPP. These results suggest that the pathway for terpenoid hydrocarbon biosynthesis in B. braunii is quite unique although cooperation of BSS, SSL-1, SSL-2, and SSL-3 is still unclear (Niehaus et al., 2011). After the synthesis, both squalene and botryococcene are subsequently methylated but the number of methylation is variable. The name of botryococcene was originally designated to methylated botryococcene but now it is used for both compounds. The methyl group is transferred from $S$-adenosyl methionine by triterpene methyltransferases (TMTs) although completely methylated (tetra-methylated) squalene and botryococcene is not yet produced in vitro (Niehaus et al., 2012). 


\section{Carbon flow and energy balance in lipid and hydrocarbon biosynthetic pathways}

In Table 3 and Fig. 1, lipid and hydrocarbon biosynthetic pathways are summarized. All hydrocarbons are produced from precursors (namely acyl-ACP or IPP/DMAPP) which are produced from three primary metabolites; acetyl-CoA, pyruvate and GAP. GAP should be the primary metabolite during photosynthesis and transported into the cytosol. Then acetyl-CoA and pyruvate are sequentially produced from GAP in the glycolysis. On the other hand, acetylCoA is primarily produced by the degradation of various lipids via $\beta-, \alpha-$, and $\omega$ - oxidation (Graham \& Eastmond, 2002). Any pathway for hydrocarbon production includes decarboxylation of carbon chain supplied as substrate and consumption of ATP and reducing power (see the MVA/MEP pathway and glycolysis in Fig. 1). GAP production mostly depends on carbon fixation rate by the photosynthetic $C_{3}$ cycle and the process seems to be the most effective limiting factor for hydrocarbon production. Gene expression level for fatty acid synthesis is relatively higher in race A (fatty hydrocarbon) than race B (terpenoid hydrocarbon) in $B$. braunii while the expression of isoprene synthetic genes showed opposite trend (Ioki et al., 2012c). Transcriptional regulation network of fatty acid metabolism is well studied in E. coli (Fujita et al., 2007) but not yet in the other organisms. Carbon allocation into lipids is known to be affected by environmental change via metabolic regulation; e.g. wax ester fermentation in E. gracilis under anaerobic conditions (Tucci et al., 2010), TG accumulation in algae under nutrient deficiency such as nitrogen (Hu et al., 2008; Miao \& Wu, 2006) and under cold-stress (Li et al., 2011; Renaud et al., 1995). On the other hand, such environmental changes do not affect carbon allocation into hydrocarbon in B. braunii (Baba et al., 2012b; Metzger \& Largeau, 2005; Sakamoto et al., 2012).

Supply of inorganic and organic carbon sources, nutrient deficiency and low-temperature are empirically known to be stimulating factors for lipid biosynthesis. Enrichment of $\mathrm{CO}_{2}$ as inorganic carbon source stimulated lipid biosynthesis and cell growth by accelerating photosynthetic carbon fixation in microalgae (Kumar et al., 2010). Neutral lipid production and accumulation was strongly accelerated in the presence of exogenous organic carbon source by accompanying with abolishing chlorophylls in a unicellular green alga Chlorella protothecoides (Miao \& Wu, 2006). Nitrogen is the most effective factor for changing carbon/nitrogen metabolism and stimulates neutral lipid accumulation under $\mathrm{N}$-deficient conditions (Hu et al., 2008). However, nitrogen deficiency diminishes whole cellular productivity and therefore the metabolic regulation to stimulating lipid biosynthesis does not always result in the increase in gross productivity of lipids. Lipid accumulation under cold (Li et al., 2011; Renaud et al., 1995) or other stress conditions (e.g., nutrient limitation at the stationary growth phase) also induce change in metabolisms. Either cold or high-salinity stress (Lu et al., 2009) stimulates lipid desaturation catalyzed by various lipid desaturases. Desaturation degree influences properties of lipids such as melting point, reactivity, odor, degradability and so on. Lipid biosynthesis by microalgae was shown to be affected by changing wavelength, namely stimulation of lipid production by red light, via the modulation of nitrogen and carbon metabolism in the cells (Miyachi et al., 1978). 


\begin{tabular}{|c|c|c|c|}
\hline Name & Reactions & Products & Notes \\
\hline \multicolumn{4}{|l|}{ Carbon chain biosynthesis } \\
\hline \multirow[t]{2}{*}{ Fatty acid biosynthesis (C2) } & acyl $(n)-A C P+$ acetyl-CoA $\left(+\mathrm{CO}_{2}\right)+A T P+2 \mathrm{NADPH}+2 \mathrm{H}^{+} \rightarrow$ acyl $(\mathrm{n}$ & Fatty & Reference \\
\hline & $+2)-\mathrm{ACP}\left(+\mathrm{CO}_{2}\right)+\mathrm{H}_{2} \mathrm{O}+\mathrm{CoA}+\mathrm{ADP}+\mathrm{Pi}+2 \mathrm{NADP}^{+}$ & $\operatorname{acid}(C 4 \sim 18)$ & pathway \\
\hline \multirow[t]{2}{*}{ Fatty acid biosynthesis (C2) } & acyl(n)-CoA + acetyl-CoA $+2 \mathrm{NADPH}+2 \mathrm{H}^{+} \rightarrow$ acyl $(n+2)-\mathrm{CoA}+\mathrm{H}_{2} \mathrm{O}$ & Fatty & E. gracilis \\
\hline & $+\mathrm{CoA}+2 \mathrm{NADP}^{+}$ & $\operatorname{acid}(C 4 \sim 16)$ & mitochondria \\
\hline \multirow[t]{2}{*}{ Fatty acid biosynthesis (C2) } & acyl $(n)-\mathrm{CoA}+$ acetyl-CoA $+2 \mathrm{NADPH}+2 \mathrm{H}^{+} \rightarrow$ acyl $(n+2)-\mathrm{CoA}+\mathrm{H}_{2} \mathrm{O}$ & Fatty & Engineered \\
\hline & $+\mathrm{CoA}+2 \mathrm{NADP}^{+}$ & $\operatorname{acid}(C 4 \sim 18)$ & Escherichia coli \\
\hline \multirow[t]{2}{*}{ MVApathway (C5) } & 3acetyl- $\mathrm{CoA}+\mathrm{H}_{2} \mathrm{O}+3 \mathrm{ATP}+2 \mathrm{NADPH}+2 \mathrm{H}^{+} \rightarrow \mathrm{IPP}+3 \mathrm{CoA}+\mathrm{CO}_{2}+$ & Isoprene & Reference \\
\hline & $3 \mathrm{ADP}+\mathrm{Pi}+2 \mathrm{NADP}^{+} ; \mathrm{IPP} \rightleftharpoons \mathrm{DMAPP}$ & & pathway \\
\hline \multirow[t]{2}{*}{ MEP pathway (C5) } & pyruvate + GAP + ATP + CTP + NADPH + 4e $+5 \mathrm{H}^{+} \rightarrow I P P($ DMAPP $)+$ & Isoprene & Incomplete about \\
\hline & $\mathrm{CO}_{2}+2 \mathrm{H}_{2} \mathrm{O}+\mathrm{ADP}+\mathrm{CMP}+\mathrm{PPi}+\mathrm{NADP}^{+}$ & & redox \\
\hline \multicolumn{4}{|l|}{ Carbon chain elongation } \\
\hline \multirow[t]{2}{*}{ Fatty acid elongation (C2) } & acyl $(n)-C o A+$ acetyl-CoA $\left(+\mathrm{CO}_{2}\right)+\mathrm{ATP}+2 \mathrm{NADPH}+2 \mathrm{H}^{+} \rightarrow$ acyl $(\mathrm{n}$ & Fatty & Reference \\
\hline & $+2)-\mathrm{CoA}\left(+\mathrm{CO}_{2}\right)+\mathrm{H}_{2} \mathrm{O}+\mathrm{CoA}+\mathrm{ADP}+\mathrm{Pi}+2 \mathrm{NADP}^{+}$ & $\operatorname{acid}(C 20 \sim 28)$ & pathway \\
\hline \multirow[t]{2}{*}{ Fatty acid elongation (C2) } & acyl(n)-CoA + acetyl-CoA $+2 \mathrm{NADPH}+2 \mathrm{H}^{+} \rightarrow$ acyl $(n+2)-\mathrm{CoA}+\mathrm{H}_{2} \mathrm{O}$ & Fatty & Human \\
\hline & $+\mathrm{CoA}+2 \mathrm{NADP}^{+}$ & $\operatorname{acid}(C 6 \sim 16)$ & mitochondria \\
\hline Head-to-tail & (n)isoprene & Terpenoid & Reference reaction \\
\hline isoprene condensation (C5) & $\rightarrow$ Poly terpenoid-PP $+(n-1) P P i(n \geq 2)$ & & \\
\hline Head-to-head & 2 isoprene + NADPH & Hydro- & Reference reaction \\
\hline isoprene condensation (C5) & $\rightarrow$ Poly terpenoid $+2 \mathrm{PPi}+\mathrm{NADP}^{+}+\mathrm{H}^{+}$ & carbon & \\
\hline \multicolumn{4}{|l|}{ Fatty acid $(A C P / C O A)$ reduction } \\
\hline \multirow[t]{2}{*}{ Fatty aldehyde formation } & acyl-CoA + NADPH + $\mathrm{H}^{+}$ & Fatty- & Reference reaction \\
\hline & $\rightarrow$ fatty aldehyde $+\mathrm{CoA}+\mathrm{NADP}^{+}$ & aldehyde & \\
\hline \multirow[t]{2}{*}{ Fatty aldehyde formation } & acyl-ACP + NADPH + $\mathrm{H}^{+}$ & Fatty- & Cyanobacteria \\
\hline & $\rightarrow$ fatty aldehyde + ACP + NADP+ & aldehyde & \\
\hline \multirow[t]{2}{*}{ Alcohol formation } & acyl-CoA + 2NADPH + 2H+ & Fatty- & Reference reaction \\
\hline & $\rightarrow$ fatty alcohol + CoA + 2NADP+ & alcohol & \\
\hline \multirow[t]{2}{*}{ Alcohol formation } & fatty aldehyde $+\mathrm{NADPH}+\mathrm{H}^{+}$ & Fatty- & Reference reaction \\
\hline & $\rightarrow$ fatty alcohol + NADP + & alcohol & \\
\hline \multirow{2}{*}{\multicolumn{4}{|c|}{$\begin{array}{l}\text { Odd-chain fatty hydrocarbon } \\
\text { biosynthesis }\end{array}$}} \\
\hline & & & \\
\hline \multirow[t]{2}{*}{ Aldehyde decarbonylation } & fatty aldehyde(n) & Hydro- & Reference reaction \\
\hline & $\rightarrow$ fatty hydrocarbon $(\mathrm{n}-1)+\mathrm{CO}$ & carbon & \\
\hline \multirow{2}{*}{\multicolumn{4}{|c|}{$\begin{array}{l}\text { Even-chain fatty hydrocarbon } \\
\text { biosynthesis }\end{array}$}} \\
\hline & & & \\
\hline \multirow[t]{2}{*}{ Alcohol reduction } & fatty alcohol (n) & Hydro- & Incomplete about \\
\hline & $\rightarrow$ fatty hydrocarbon (n) & carbon & redox \\
\hline \multicolumn{4}{|l|}{ Olefinic hydrocarbon } \\
\hline Head-to-head & 2 acyl-CoA(n) & Hydro- & Incompletely \\
\hline acyl-CoA condensation & $\rightarrow$ alkadiene $(2 \mathrm{n}-1)+\mathrm{CO}_{2}+\mathrm{H}_{2} \mathrm{O}+2 \mathrm{CoA}$ & carbon & understood \\
\hline \multicolumn{4}{|l|}{ Wax ester } \\
\hline \multirow[t]{2}{*}{ Fatty acid/alcohole sterification } & fatty acyl-CoA $(X)+$ fatty alcohol(Y) & Wax ester & Reference reaction \\
\hline & $\rightarrow$ wax ester $(X+Y)+$ CoA & & \\
\hline
\end{tabular}

Table 3. Carbon flow, consumption of ATP and reducing power in lipid and hydrocarbon biosynthetic pathways 


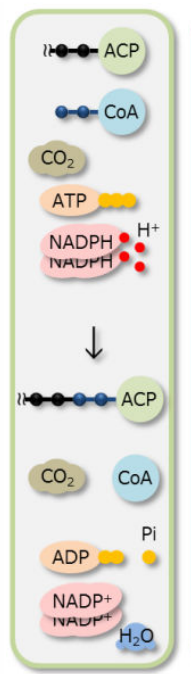

Fatty acid biosynthesis in plastida

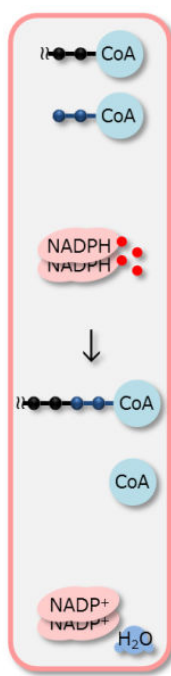

Fatty acid biosynthesis in mitochondria ${ }^{a}$
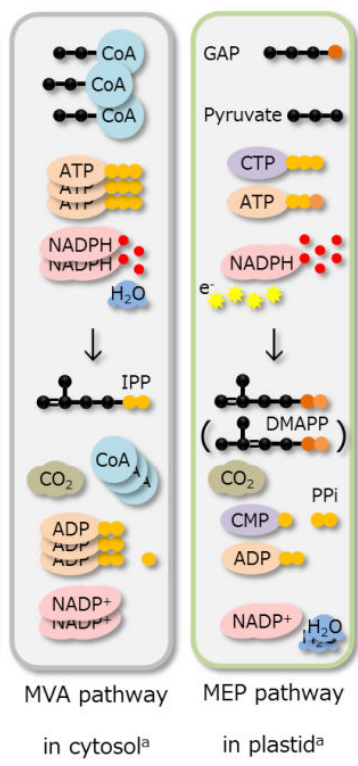

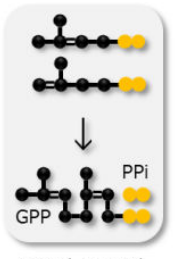

Head-to-tail isoprene condensation

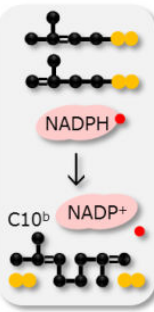

Head-to-head isoprene condensation

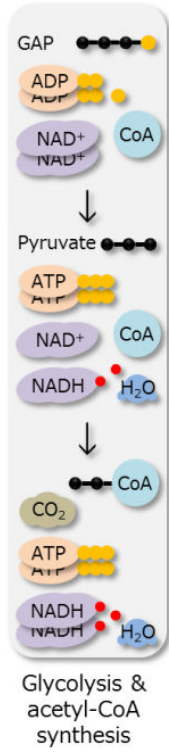

Representative localization of pathways in algae and plants.

${ }^{\mathrm{b}} \mathrm{C} 10$, mono-terpene is indicated as a model product which is typically synthesized via GPP in vivo.

Figure 2. Carbon flow, consumption of ATP and reducing power in lipid biosynthetic pathways. Black- or blue-chained spheres indicate C-C chain. Orange- or Yellow-colored circles indicate Pi in various compounds including IPP, DMAPP, ATP and so on. Difference in color of box-frames indicates difference in localization of pathways. Fatty acid biosynthesis in engineered $E$. coli and fatty acid $\left(\sim C_{4}\right)$ elongation in human mitochondria are not shown here since those reactions are same as those in mitochondria of $E$. gracilis; namely, reversal pathway of $\beta$-oxidation. Detailed information is written in the text. GPP, geranyl diphosphate.

\section{Future perspective of algal lipid biosynthetic pathways}

Recent in silico analysis suggested the presence of some unique lipid-metabolic pathways in algae although those are not characterized yet (e.g., see Table3 and 3. Hydrocarbon biosynthesis in algae). Therefore, research on algal lipid biosynthetic pathways should be unavoidably worthy task to increase industrial algal-oil production. Study on lipid metabolism is also beneficial for useful and biologically active organic material production to achieve the invention of manufactural lipid synthesis. One of such good examples is the manipulation of $\beta$-oxidation to proceed for reversal direction in E. coli (Dellomonaco et al., 2011), the construction of recursive " +1 " pathway by genetic engineering in contrast to " +2 " fatty acid and " +5 " isoprene pathways (Marcheschi et al., 2012). Increase in lipid production by eukaryotic algae strongly can be achieved by metabolic manipulation by controlling strict redox status and subcellular compartment of metabolisms. 
Genetic engineering in eukaryotic algae is important technology to be established although it still is quite challenging (Gong et al., 2011; Radakovits et al., 2010). It is highly expected that algal oil is efficiently produced with high purity since it is produced by enzymatic reactions in homogenous productive cells. So, characteristics of products, such as chain length and number of double bond in the molecule, can be modified by genetic engineering (Gong \& Jiang, 2011; Radakovits et al., 2010). Further, facilitation of lipid extraction (e.g. lipid auto-secretion from cells to the medium) (Cho \& Cronan, 1995; Liu et al., 2010; Michinaka et al., 2003; Nojima et al., 1999) and cell precipitation control (Kawano et al., 2011)) are important to be improved since such processes consume vast energy at industrial process of production. It is noteworthy that direct extraction of oil from B. braunii was already achieved to reduce energy and cost (Frenz et al., 1989; Kanda et al., in press). In cyanobacteria, trial to generate hydrocarbon tolerant species was just started (Liu et al., 2012).

Finding of limiting step in whole photosynthetic $\mathrm{CO}_{2}$ fixation process is also important to increase lipid productivity. Algae have evolved by developing ability to facilitate the utilization of ambient level of $\mathrm{CO}_{2}$ by the action of innate $\mathrm{CO}_{2}$ concentrating mechanisms (Giordano et al., 2005; Raven, 2010). Exogenous $\mathrm{CO}_{2}$ supplementation recovers cells from $\mathrm{CO}_{2}$-limitation when cells are exposed such conditions within few hours. However, the photosynthetic activity quickly changes to optimize their ability to exposed conditions since algal cells possess ability to adapt/acclimate to environmental change. The maximal carbon fixation rate and high$\mathrm{CO}_{2}$ tolerance are highly depend on microalgal species/strain and therefore $\mathrm{CO}_{2}$-enrichment is not so beneficial for the improvement of cost and energy performance of microalgal production (Baba \& Shiraiwa, 2012). Further investigation is necessary to produce newlyengineered algal cells which exhibit high and efficient $\mathrm{CO}_{2}$-utilization and -fixation ability with enhanced photosynthesis and lipid productivity.

\section{Acknowledgements}

This work was financially supported, in part, by a Grant-in-Aid for Scientific Research from the Core Research of Evolutional Science \& Technology (CREST) program from the Japan Science and Technology Agency (JST) (to YS).

\section{Author details}

Masato Baba ${ }^{1,2}$ and Yoshihiro Shiraiwa ${ }^{1,2}$

1 Faculty of Life and Environmental Sciences, University of Tsukuba, Tsukuba, Ibaraki, Japan

2 CREST, JST, Japan 


\section{References}

[1] Albro, P. W, \& Dittmer, J. C. (1969). The Biochemistry of Long-chain Nonisoprenoid Hydrocarbons. III. The Metabolic Relationship of Long-chain Fatty Acids and Hydrocarbons and Other Aspects of Hydrocarbon Metabolism in Sarcina lutea. Biochemistry,May 1969), 0006-2960, 8(5), 1913-1918.

[2] Alvarez, H. M, \& Steinbüchel, A. (2002). Triacylglycerols in Prokaryotic Microorganisms. Applied microbiology and biotechnology, December 2002), 0175-7598, 60(4), 367-376.

[3] Awai, K, \& Wolk, C. P. (2007). Identification of the Glycosyl Transferase Required for Synthesis of the Principal Glycolipid Characteristic of Heterocysts of Anabaena Sp. Strain PCC 7120. FEMS Microbiology Letters, November 2007), 0378-1097, 226, 98-102.

[4] Baba, M, \& Shiraiwa, Y. (2012). High- $\mathrm{CO}_{2}$ Response Mechanisms in Microalgae, In: Advances in Photosynthesis- Fundamental Aspects-. Edited by Najafpour, M., InTech, 978-9-53307-928-8Rijeka, Croatia.

[5] Baba, M, Ioki, M, Nakajima, N, Shiraiwa, Y, \& Watanabe, M. M. (2012a). Transcriptome Analysis of an Oil-rich Race A Strain of Botryococcus Braunii (BOT-88-2) by de novo Assembly of Pyrosequencing cDNA Reads. Bioresource technology, April 2012), 0960-8524, 109, 282-286.

[6] Baba, M, Kikuta, F, Suzuki, I, Watanabe, M. M, \& Shiraiwa, Y. (2012b). Wavelength Specificity of Growth, Photosynthesis, and Hydrocarbon Production in the Oil-producing Green Alga Botryococcus braunii. Bioresource technology, May 2012), 0960-8524, 109, 266-270.

[7] Banerjee, A, Sharma, R, Chisti, Y, \& Banerjee, U. C. (2002). Botryococcus braunii: A Renewable Source of Hydrocarbons and Other Chemicals. Critical reviews in biotechnology, 0738-8551, 22(3), 245-279.

[8] Bauersachs, T, Compaoré, J, Hopmans, E. C, Stal, L. J, Schouten, S, \& Sinninghe, J. S. (2009). Phytochemistry Distribution of Heterocyst Glycolipids in Cyanobacteria. Phytochemistry, September 2009), 0031-9422, 70(17-18), 2034-2039.

[9] Beller, H. R, Goh, E, \& Keasling, J. D. (2010). Genes Involved in Long-Chain Alkene Biosynthesis in Micrococcus luteus. Applied and environmental microbiology, February 2010), 0099-2240, 76(4), 1212-1223.

[10] Bouvier, F, Rahier, A, \& Camara, B. (2005). Biogenesis, Molecular Regulation and Function of Plant Isoprenoids. Progress in lipid research, November 2005), 0163-7827, 44(6), 357-429.

[11] Casadevall, E, Dif, D, Largeau, C, Gudin, C, Chaumont, D, \& Desanti, O. (1985). Studies on Batch and Continuous Cultures of Botryococcus braunii: Hydrocarbon 
Production in Relation to Physiological State, Cell Ultrastructure, and Phosphate Nutrition. Biotechnology and bioengineering, March 1985), 0006-3592, 27(3), 286-295.

[12] Chan, D. I, \& Vogel, H. J. (2010). Current Understanding of Fatty Acid Biosynthesis and the Acyl Carrier Protein. The Biochemical journal, August 2010), 0264-6021, 430(1), 1-19.

[13] Cheesbrough, M, \& Kolattukudy, P. E. (1984). Particulate Preparation from Pisum sativum. Proceedings of the national academy of sciences of the United States of America, November 1984), 0027-8424, 81, 6613-6617.

[14] Cho, H, \& Cronan, J. E. Jr. ((1995). Defective Export of a Periplasmic Enzyme Disrupts Regulation of Fatty Acid Synthesis. The Journal of biological chemistry, March 1995), 0021-9258, 270(9), 4216-4219.

[15] Dellomonaco, C, Clomburg, J. M, Miller, E. N, \& Gonzalez, R. (2011). Engineered Reversal of the $\beta$-oxidation Cycle for the Synthesis of Fuels and Chemicals. Nature, August 2011), 0028-0836, 476(7360), 355-359.

[16] Dennis, M. W, \& Kolattukudy, P. E. (1991). Alkane Biosynthesis by Decarbonylation of Aldehyde Catalyzed by a Microsomal Preparation from Botryococcus braunii. Archives of biochemistry and biophysics, June 1991), 0003-9861, 287(2), 268-275.

[17] Dennis, M, \& Kolattukudy, P. E. Enzyme Converts a Fatty Aldehyde to a Hydrocarbon and CO. Proceedings of the national academy of sciences of the United States of America, June 1992), 0027-8424, 89(12), 5306-5310.

[18] Eltgroth, M. L, Watwood, R. L, \& Gordon, V. (2005). Production and Cellular Localization of Neutral Long-Chain Lipids in the Haptophyte Algae Isochrysis galbana and Emiliania huxleyi. Journal of phycology, 0022-3646, 41, 1000-1009.

[19] Frenz, J, Largeau, C, Casadevall, E, Kollerup, F, \& Daugulis, A. J. (1989). Hydrocarbon Recovery and Biocompatibility of Solvents for Extraction from Cultures of Botryococcus braunii. Biotechnology and bioengineering, September 1989), 0006-3592, 34(6), 755-762.

[20] Fujita, Y, Matsuoka, H, \& Hirooka, K. (2007). Regulation of Fatty Acid Metabolism in Bacteria. Molecular microbiology, November 2007), 0095-0382X., 66(4), 829-839.

[21] Giordano, M, Beardall, J, \& Raven, J. A. (2005). $\mathrm{CO}_{2}$ Concentrating Mechanisms in Algae: Mechanisms, Environmental Modulation, and Evolution. Annual review of plant biology, June 2005), 1543-5008ISSN: 1543-5008., 56, 99-131.

[22] Gong, Y, \& Jiang, M. (2011). Biodiesel Production with Microalgae as Feedstock: From Strains to Biodiesel. Biotechnology letters, July 2011), 0141-5492, 33(7), 1269-1284.

[23] Gong, Y, Hu, H, Gao, Y, Xu, X, \& Gao, H. (2011). Microalgae as Platforms for Production of Recombinant Proteins and Valuable Compounds: Progress and Prospects. 
Journal of industrial microbiology \& biotechnology, December 2011), 1367-5435, 38(12), 1879-1890.

[24] Graham, I. A, \& Eastmond, P. J. (2002). Pathways of Straight and Branched Chain Fatty Acid Catabolism in Higher Plants. Progress in lipid research, March 2002), 0163-7827, 41(2), 156-181.

[25] Gu, P, \& Ishii, Y. Spencer, T. a \& Shechter, I. ((1998). Function-structure Studies and Identification of Three Enzyme Domains Involved in the Catalytic Activity in Rat Hepatic Squalene Synthase. The Journal of biological chemistry, May 1998), 0021-9258, 273(20), 12515-12525.

[26] Hiltunen, J. K, Chen, Z, Haapalainen, A. M, Wierenga, R. K, \& Kastaniotis, A. J. (2010). Mitochondrial Fatty Acid Synthesis- An Adopted Set of Enzymes Making a Pathway of Major Importance for the Cellular Metabolism. Progress in lipid research, January 2010), 0163-7827, 49(1), 27-45.

[27] Hlousek-radojcic, A, Evenson, K. J, Jaworski, J. G, \& Post-beittenmiller, D. (1998). Fatty Acid Elongation Is Independent of Acyl-Coenzyme A Synthetase Activities in Leek and Brassica napus. Phytochemistry, 0031-9422, 116, 251-258.

[28] Hoffmeister, M, Piotrowski, M, Nowitzki, U, \& Martin, W. (2005). Mitochondrial trans-2-enoyl-CoA Reductase of Wax Ester Fermentation from Euglena gracilis Defines a New Family of Enzymes Involved in Lipid Synthesis. The Journal of biological chemistry, February 2005), 0021-9258, 280(6), 4329-4338.

[29] Hu, Q, Sommerfeld, M, Jarvis, E, Ghirardi, M, Posewitz, M, Seibert, M, \& Darzins, A. (2008). Microalgal Triacylglycerols as Feedstocks for Biofuel Production: Perspectives and Advances. The Plant journal, May 2008), 0960-7412, 54(4), 621-639.

[30] Hunter, W. N. (2007). The Non-mevalonate Pathway of Isoprenoid Precursor Biosynthesis. The Journal of biological chemistry, July 2007), 0021-9258, 282(30), 21573-21577.

[31] Imamura, S, Hagiwara, D, Suzuki, F, Kurano, N, \& Harayama, S. (2012). Genetic Transformation of Pseudochoricystis ellipsoidea, an Aliphatic Hydrocarbon-producing Green Alga. Journal of general and applied microbiology, 0022-1260, 58(1), 1-10.

[32] Inui, H, Miyatake, K, Nakano, Y, \& Kitaoka, S. (1982). Wax Ester Fermentation in Euglena gracilis. FEBS Letters, December 1982), 0014-5793, 150(1), 89-93.

[33] Inui, H, Miyatake, K, Nakano, Y, \& Kitaoka, S. (1984). Fatty Acid Synthesis in Mitochondria of Euglena gracilis. European journal of biochemistry/FEBS, July 1984), 0014-2956, 142(1), 121-126.

[34] Ioki, M, Baba, M, Nakajima, N, Shiraiwa, Y, \& Watanabe, M. M. (2012a). Transcriptome Analysis of an Oil-rich Race B Strain of Botryococcus braunii (BOT-22) by de novo Assembly of Pyrosequencing cDNA Reads. Bioresource technology, April 2012), 0960-8524, 109, 292-296. 
[35] Ioki, M, Baba, M, Nakajima, N, Shiraiwa, Y, \& Watanabe, M. M. (2012b). Transcriptome Analysis of an Oil-rich Race B Strain of Botryococcus braunii (BOT-70) by de novo Assembly of 5'-end Sequences of Full-length cDNA Clones. Bioresource technology, April 2012), 0960-8524, 109, 277-281.

[36] Ioki, M, Baba, M, Bidadi, H, Suzuki, I, Shiraiwa, Y, Watanabe, M. M, \& Nakajima, N. (2012c). Modes of Hydrocarbon Oil Biosynthesis Revealed by Comparative Gene Expression Analysis for Race A and Race B Strains of Botryococcus braunii. Bioresource technology, April 2012), 0960-8524, 109, 271-276.

[37] Jenke-kodama, H, \& Dittmann, E. (2009). Evolution of Metabolic Diversity: Insights from Microbial Polyketide Synthases. Phytochemistry, July 2009), 0031-9422, 70(15-16), 1858-1866.

[38] Jennings, S. M, Tsay, Y. H, Fisch, T. M, \& Robinson, G. W. (1991). Molecular Cloning and Characterization of the Yeast Gene for Squalene Synthetase. Proceedings of the National Academy of Sciences of the United States of America, July 1991), 0027-8424, 88(14), 6038-6042.

[39] Jetter, R, \& Kunst, L. (2008). Plant Surface Lipid Biosynthetic Pathways and Their Utility for Metabolic Engineering of Waxes and Hydrocarbon Biofuels. The Plant journal: for cell and molecular biology, May 2008), 0960-7412, 54(4), 670-683.

[40] John, U, Beszteri, B, \& Derelle, E. Van de Peer, Y.; Read, B.; Moreau, H. \& Cembella, A. ((2008). Novel Insights into Evolution of Protistan Polyketide Synthases Through Phylogenomic Analysis. Protist, January 2008), 1434-4610, 159(1), 21-30.

[41] Joyard, J, Ferro, M, Masselon, C, Seigneurin-berny, D, Salvi, D, Garin, J, \& Rolland, N. (2009). Chloroplast Proteomics and the Compartmentation of Plastidial Isoprenoid Biosynthetic Pathways. Molecular Plant, November 2009), 1674-2052, 2(6), 1154-1180.

[42] Joyard, J, Ferro, M, Masselon, C, Seigneurin-berny, D, Salvi, D, Garin, J, \& Rolland, N. (2010). Chloroplast Proteomics Highlights the Subcellular Compartmentation of Lipid Metabolism. Progress in lipid research, April 2010), 0163-7827, 49(2), 128-158.

[43] Kanda, H, Li, P, Yoshimura, T, \& Okada, S. in press) Wet Extraction of Hydrocarbons from Botryococcus braunii by Dimethyl Ether as Compared with Dry Extraction by Hexane. Fuel,0016-2361

[44] Kaneda, T. (1991). Iso- and Anteiso-fatty Acids in Bacteria: Biosynthesis, Function, and Taxonomic Significance. Microbiological reviews, June 1991), 0146-0749, 55(2), 288-302.

[45] Kawano, Y, Saotome, T, Ochiai, Y, Katayama, M, Narikawa, R, \& Ikeuchi, M. (2011). Cellulose Accumulation and a Cellulose Synthase Gene Are Responsible for Cell Aggregation in the Cyanobacterium Thermosynechococcus vulcanus RKN. Plant \& cell physiology, June 2011), 0032-0781, 52(6), 957-966. 
[46] Kumar, A, Ergas, S, Yuan, X, Sahu, A, Zhang, Q, Dewulf, J, Malcata, F. X, \& Van Langenhove, $\mathrm{H}$. fixation and biofuel production via microalgae: recent developments and future directions. Trends in Biotechnology, July), 0167-7799, 28(7), 371-380.

[47] Kunst, L, \& Samuels, L. (2009). Plant Cuticles Shine: Advances in Wax Biosynthesis and Export. Current opinion in plant biology, October 2009), 1369-5266, 12, 721-727.

[48] Largeau, C, Casadevall, E, \& Berkaloff, B. (1980). The Biosynthesis of Long-chain Hydrocarbons in the Green Alga Botryococcus braunii. Phytochemistry, 0031-9422, 19(6), 1081-1085.

[49] Laws, E. A, Popp, B. N, Bidigare, R. R, Riebesell, U, Burkhardt, S, \& Wakeham, S. G. (2001). Controls on the Molecular Distribution and Carbon Isotopic Composition of Alkenones in Certain Haptophyte Algae. Geochemistry geophysics geosystems, January 2001), Paper 0025-3227, 2(2000GC000057)

[50] Lee, S. H, Stephens, J. L, Paul, K. S, \& Englund, P. T. (2006). Fatty Acid Synthesis by Elongases in Trypanosomes. Cell, August 2006), 0092-8674, 126(4), 691-699.

[51] Li, F, Wu, X, Lam, P, Bird, D, Zheng, H, Samuels, L, Jetter, R, \& Kunst, L. (2008). Identification of the Wax Ester Synthase/acyl-coenzyme A: Diacylglycerol Acyltransferase WSD1 Required for Stem Wax Ester Biosynthesis in Arabidopsis. Plant physiology, September 2008), 0032-0889, 148(1), 97-107.

[52] Li, X, Hu, H, \& Zhang, Y. (2011). Growth and Lipid Accumulation Properties of a Freshwater Microalga Scenedesmus Sp. Under Different Cultivation Temperature. Bioresource technology, February 2011), 0960-8524, 102(3), 3098-3102.

[53] Liu, X, Brune, D, Vermaas, W, \& Curtiss, R. III. ((2010). Production and Secretion of Fatty Acids in Genetically Engineered Cyanobacteria. Proceedings of the National Academy of Sciences of the United States of America, July 2010), 0027-8424, 6803(19)

[54] Liu, J, Chen, L, Wang, J, Qiao, J, \& Zhang, W. (2012). Proteomic Analysis Reveals Resistance Mechanism Against Biofuel Hexane in Synechocystis Sp. PCC 6803. Biotechnology for biofuels, January 2012), 1754-6834, 5(1), 68.

[55] Lohr, M, Schwender, J, \& Polle, J. E. W. (2012). Isoprenoid Biosynthesis in Eukaryotic Phototrophs: A Spotlight on Algae. Plant science : an international journal of experimental plant biology, April 2012) 0168-9452, 185-186, 9-22.

[56] Lu, Y. D, Chi, X, Yang, Q, Li, Z, Liu, S, Gan, Q, \& Qin, S. (2009). Molecular cloning and stress-dependent expression of a gene encoding Delta(12)-fatty acid desaturase in the Antarctic microalga Chlorella vulgaris NJ-7. Extremophiles: life under extreme conditions, November), 1431-0651, 13(6), 875-884.

[57] Marcheschi, R. J, Li, H, Zhang, K, Noey, E. L, Kim, S, Chaubey, A, Houk, K. N, \& Liao, J. C. (2012). A Synthetic Recursive “+1" Pathway for Carbon Chain Elongation. ACS chemical biology, April 2012), 1554-8929, 7(4), 689-697. 
[58] Matsushima, D, Jenke-kodama, H, Sato, Y, Fukunaga, Y, Sumimoto, K, Kuzuyama, T, Matsunaga, S, \& Okada, S. (2012). The Single Cellular Green Microalga Botryococcus braunii, Race B Possesses Three Distinct 1-deoxy-D-xylulose 5-phosphate Synthases. Plant science: an international journal of experimental plant biology, April 2012), 0168-9452, 185-186, 309-320.

[59] Metzger, P, \& Largeau, C. (2005). Botryococcus braunii: a Rich Source for Hydrocarbons and Related Ether Lipids. Applied Microbiology, December 2004), 0003-6919, 66, 486-496.

[60] Metzger, P, Pouet, Y, Bischoff, R, \& Casadeval, E. (1993). An Aliphatic Polyaldehyde from Botryococcus braunii (A Race). Phytochemistry, 0031-9422, 32(4), 875-883.

[61] Metzger, P, Rager, M, \& Largeau, N. C. ((2007). Polyacetals Based on Polymethylsqualene Diols, Precursors of Algaenan in Botryococcus braunii Race B. Organic geochemistry, April 2007), 0146-6380, 38(4), 566-581.

[62] Metzger, P, Rager, M, Fosse, N, \& Braunicetals, C. Acetals from Condensation of Macrocyclic Aldehydes and Terpene Diols in Botryococcus braunii. Phytochemistry, September 2008), 0031-9422, 69(12), 2380-2386.

[63] Miao, X, \& Wu, Q. (2006). Biodiesel Production from Heterotrophic Microalgal Oil. Bioresource technology, April 2006), 0960-8524, 97(6), 841-846.

[64] Michinaka, Y, Shimauchi, T, Aki, T, Nakajima, T, Kawamoto, S, Shigeta, S, Suzuki, O, \& Ono, K. (2003). Extracellular Secretion of Free Fatty Acids by Disruption of a Fatty acyl-CoA Synthetase Gene in Saccharomyces cerevisiae. Journal of bioscience and bioengineering, January 2003), 1347-4421, 95(5), 435-440.

[65] Miyachi, S, Miyachi, S, \& Kamiya, A. (1978). Wavelength effects on photosynthetic carbon metabolism in Chlorella. Plant and Cell Physiology, 0032-0781, 19(2), 277-288.

[66] Moore, B. S. (2006). Biosynthesis of Marine Natural Products: Macroorganisms (Part B). Natural product reports, August 2006), 0265-0568, 23(4), 615-629.

[67] Nicolaisen, K, Hahn, A, \& Schleiff, E. (2009). The Cell Wall in Heterocyst Formation by Anabaena Sp. PCC 7120. Journal of basic microbiology, February 2009), 0023-3111X., 49, 5-24.

[68] Niehaus, T. D, Okada, S, Devarenne, T. P, Watt, D. S, Sviripa, V, \& Chappell, J. (2011). Identification of Unique Mechanisms for Triterpene Biosynthesis in Botryococcus braunii. Proceedings of the national academy of sciences of the United States of America, July 2011), 0027-8424, 108(30), 12260-12265.

[69] Niehaus, T. D, Kinison, S, Okada, S, \& Yeo, Y. Bell, S. a; Cui, P.; Devarenne, T. P. \& Chappell, J. ((2012). Functional Identification of Triterpene Methyltransferases from Botryococcus braunii Race B. The Journal of biological chemistry, March 2012), 0021-9258, 287(11), 8163-8173. 
[70] Nojima, Y, Kibayashi, A, Matsuzaki, H, Hatano, T, \& Fukui, S. (1999). Isolation and Characterization of Triacylglycerol-secreting Mutant Strain from Yeast, Saccharomyces cerevisiae. The Journal of general and applied microbiology, February 1999), 0022-1260, 45(1), 1-6.

[71] Okada, S, Devarenne, T. P, \& Chappell, J. (2000). Molecular Characterization of Squalene Synthase from the Green Microalga Botryococcus braunii, Race B. Archives of biochemistry and biophysics, January 2000), 0003-9861, 373(2), 307-317.

[72] Okada, S. (2012). Chapter 7 Elucidation of hydrocarbon synthetic pathway in Botryococcus braunii, In: Technology of Microalgal Energy Production and its Business Prospect. Edited by Takeyama, H. CMC, 978-4-78130-657-5Osaka, Japan.

[73] Park, M. (2005). New Pathway for Long-Chain n-Alkane Synthesis via 1-Alcohol in Vibrio furnissii M1. Journal of bacteriology, February 2005), 0021-9193, 187(4), 1426-1429.

[74] Poliquin, K, Ershov, Y. V, \& Cunningham, F. X. Jr; Woreta, T. T.; Gantt, R. R. \& Gantt, E. \& ((2004). Inactivation of sll1556 in Synechocystis Strain PCC 6803 Impairs Isoprenoid Biosynthesis from Pentose Phosphate Cycle Substrates In Vitro. Journal of bacteriology, July 2004), 0021-9193, 186(14), 4685-4693.

[75] Portevin, D. De Sousa-D'Auria, C.; Houssin, C.; Grimaldi, C.; Chami, M.; Daffé, M. \& Guilhot, C. ((2004). A Polyketide Synthase Catalyzes the Last Condensation Step of Mycolic Acid Biosynthesis in Mycobacteria and Related Organisms. Proceedings of the national academy of sciences of the United States of America, January 2004), 0027-8424, 101(1), 314-319.

[76] Radakovits, R, Jinkerson, R. E, Darzins, A, \& Posewitz, M. C. (2010). Genetic Engineering of Algae for Enhanced Biofuel Production. Eukaryotic cell, April 2010), 1535-9786, 9(4), 486-501.

[77] Raven, J. A. (2010). Inorganic Carbon Acquisition by Eukaryotic Algae: Four Current Questions. Photosynthesis research, June 2010), 1573-5079ISSN: 0166-8595., 106(1-2), 123-134.

[78] Renaud, S. M, Zhou, H. C, Parry, D. L, Thinh, L, \& Woo, K. C. (1995). Effect of Temperature on the Growth, Total Lipid Content and Fatty Acid Composition of Recently Isolated Tropical Microalgae Isochrysis Sp., Nitzschia Closterium, Nitzschia Paleacea, and Commercial Species Isochrysis Sp. (Clone T.ISO). Journal of Applied Phycology, December 1995), 0921-8971, 7(6), 595-602.

[79] Rezanka, T, \& Sigler, K. (2009). Progress in Lipid Research Odd-numbered Verylong-chain Fatty Acids from the Microbial, Animal and Plant Kingdoms. Progress in lipid research, March 2009), 0163-7827, 48(3-4), 206-238. 
[80] Riekhof, W. R, Sears, B. B, \& Benning, C. (2005). Annotation of Genes Involved in Glycerolipid Biosynthesis in Chlamydomonas reinhardtii: Discovery of the Betaine Lipid Synthase BTA1. Eukaryotic cell, February 2005), 1535-9786, 4(2), 242-252.

[81] Sakamoto, K, Baba, M, Suzuki, I, Watanabe, M. M, \& Shiraiwa, Y. (2012). Optimization of Light for Growth, Photosynthesis, and Hydrocarbon Production by the Colonial Microalga Botryococcus braunii BOT-22. Bioresource technology, April 2012), 0960-8524, 110, 474-479.

[82] Sasso, S, Pohnert, G, Lohr, M, Mittag, M, \& Hertweck, C. (2011). Microalgae in the Post-genomic Era: A Blooming Reservoir for New Natural Products. FEMS microbiology reviews, (September 2011), 0168-6445, 1-25.

[83] Sato, Y, Ito, Y, Okada, S, Murakami, M, \& Abe, H. (2003). Biosynthesis of the Triterpenoids, Botryococcenes and Tetramethylsqualene in the B Race of Botryococcus braunii via the Non-mevalonate Pathway. Tetrahedron letters, September 2003), 0040-4039, 44(37), 7035-7037.

[84] Satoh, A, Kato, M, Yamato, K. T, Ikegami, Y, Sekiguchi, H, Kurano, N, \& Miyachi, S. (2010). Characterization of the Lipid Accumulation in a New Microalgal Species,. Pseudochoricystis ellipsoidea (Trebouxiophyceae). Journal of the Japan institute of energy, September 2010), 0916-8753, 89(9), 909-913.

[85] Schirmer, A. Rude, M. a; Li, X.; Popova, E. \& Del Cardayre, S. B. ((2010). Microbial Biosynthesis of Alkanes. Science, July 2010), 0036-8075, 329(599), 559-562.

[86] Shen, B. (2003). Polyketide Biosynthesis Beyond the Type I, II and III Polyketide Synthase Paradigms. Current Opinion in Chemical Biology, April 2003), 1367-5931, 7(2), 285-295.

[87] Staunton, J, \& Weissman, K. J. (2001). Polyketide Biosynthesis: a Millennium Review. Natural product reports, June 2001), 0265-0568, 18(4), 380-416.

[88] Sukovich, D. J, Seffernick, J. L, Richman, J. E, Hunt, K. A, Gralnick, J. A, \& Wackett, L. P. (2010a). Structure, Function, and Insights into the Biosynthesis of a Head-tohead Hydrocarbon in Shewanella oneidensis Strain MR-1. Applied and environmental microbiology, June 2010), 0099-2240, 76(12), 3842-3849.

[89] Sukovich, D. J, Seffernick, J. L, Richman, J. E, Gralnick, J. A, \& Wackett, L. P. (2010b). Widespread Head-to-Head Hydrocarbon Biosynthesis in Bacteria and Role of OleA. Applied and environmental microbiology, June 2010), 0099-2240, 76(12), 3850-3862.

[90] Tabarsa, M, Rezaei, M, Ramezanpour, Z, \& Waaland, J. R. (2012). Chemical Compositions of the Marine Algae Gracilaria salicornia (Rhodophyta) and Ulva lactuca (Chlorophyta) as a Potential Food Source. Journal of the science of food and agriculture, September 2012), 0022-5142, 92(12), 2500-2506. 
[91] Teerawanichpan, P, \& Qiu, X. (2010). Fatty acyl-CoA Reductase and Wax Synthase from Euglena gracilis in the Biosynthesis of Medium-chain Wax Esters. Lipids, March 2010), 0024-4201, 45(3), 263-273.

[92] Templier, J, Diesendorf, C, Largeau, C, \& Casadevall, E. (1992). Metabolism of n-alkadienes in the A race of Botryococcus braunii. Phytochemistry, 0031-9422, 31(1), 113-120.

[93] Toney, J. L, Theroux, S, Andersen, R. a, Coleman, A, Amaral-zettler, L, \& Huang, Y. (2012). Culturing of the First 37:4 Predominant Lacustrine Haptophyte: Geochemical, Biochemical, and Genetic Implications. Geochimica et cosmochimica acta, February 2012), 0016-7037, 78, 51-64.

[94] Tornabene, T. G. (1981). Formation of Hydrocarbons by Bacteria and Algae. Basic life sciences, January 1981), 0036-8075, 18, 421-438.

[95] Tucci, S, Vacula, R, Krajcovic, J, Proksch, P, \& Martin, W. (2010). Variability of Wax Ester Fermentation in Natural and Bleached Euglena Gracilis Strains in Response to Oxygen and the Elongase Inhibitor Flufenacet. The Journal of eukaryotic microbiology, December 2010), 1066-5234, 57(1), 63-69.

[96] Venegas-calerón, M, Sayanova, O, \& Napier, J. A. (2010). An Alternative to Fish Oils: Metabolic Engineering of Oil-seed Crops to Produce Omega-3 Long Chain Polyunsaturated Fatty Acids. Progress in lipid research, April 2010), 0163-7827, 49(2), 108-119.

[97] VerschoorJ. a; Baird, M. S. \& Grooten, J. ((2012). Towards Understanding the Functional Diversity of Cell Wall Mycolic Acids of Mycobacterium tuberculosis. Progress in lipid research, October 2012), 0163-7827, 51(4), 325-339.

[98] Vioque, J, \& Kolattukudy, P. E. (1997). Resolution and Purification of an Aldehydegenerating and an Alcohol-generating Fatty acyl-CoA Reductase from Pea Leaves (Pisum sativum L.). Archives of biochemistry and biophysics, April 1997), 0003-9861, 340(1), 64-72.

[99] Wahlen, B. D, Oswald, W. S, Seefeldt, L. C, \& Barney, B. M. (2009). Purification, Characterization, and Potential Bacterial Wax Production Role of an NADPH-dependent Fatty Aldehyde Reductase from Marinobacter aquaeolei VT8. Applied and environmental microbiology, May 2009), 0099-2240, 75(9), 2758-2764.

[100] Wang, X, \& Kolattukudy, P. E. (1995). Solubilization and Purification of Aldehydegenerating Fatty acyl-CoA Reductase from Green Alga Botryococcus braunii. FEBS letters, August 1995), 0014-5793, 370(1-2), 15-18.

[101] Weiss, T. L, Roth, R, Goodson, C, Vitha, S, Black, I, Azadi, P, Rusch, J, Holzenburg, A, Devarenne, T. P, \& Goodenough, U. (2012). Colony Organization in the Green Alga Botryococcus braunii (Race B) Is Specified by a Complex Extracellular Matrix. Eukaryotic cell, August 2012), 1535-9786, 11(12), 1424-1440.

[102] Willis, R. M, Wahlen, B. D, Seefeldt, L. C, \& Barney, B. M. (2011). Characterization of a Fatty acyl-CoA Reductase from Marinobacter aquaeolei VT8: a Bacterial Enzyme 
Catalyzing the Reduction of Fatty acyl-CoA to Fatty Alcohol. Biochemistry, December 2011), 0006-2960, 50(48), 10550-10558.

[103] Yasuno, R, Von Wettstein-knowles, P, \& Wada, H. (2004). Identification and Molecular Characterization of the Beta-ketoacyl-[acyl Carrier Protein] Synthase Component of the Arabidopsis Mitochondrial Fatty Acid Synthase. The Journal of biological chemistry, February 2004), 0021-9258, 279(9), 8242-8251.

[104] Yoshida, M, Tanabe, Y, Yonezawa, N, \& Watanabe, M. M. (2012). Energy Innovation Potential of Oleaginous Microalgae. Biofuels, November 2012), 1759-7269, 3(6), 761-781. 